\title{
PEMBERIAN KOTORAN SAPI PADA PERTANAMAN JAGUNG (Zea mays): PERUBAHAN FRAKSI FOSFOR INORGANIK PADA ULTISOL GUNUNG SINDUR, JAWA BARAT
}

\section{The Application of Cow Dung on Corn (Zea mays) Cultivation: The Changes of Inorganic Phosphorus Fractions in Ultisol Gunung Sindur, West Java}

\author{
Arief Hartono ${ }^{1)^{*}}$, Sri Djuniwati1), dan Hafiz Hernandi') \\ 1) Departemen Ilmu Tanah dan Sumberdaya Lahan, Fakultas Pertanian IPB, J1. Meranti Kampus IPB Darmaga \\ Bogor 16680 \\ 2) Alumni Program Studi Manajemen Sumberdaya Lahan Fakultas Pertanian IPB, Jl. Meranti Kampus IPB \\ Darmaga, Bogor 16680
}

\begin{abstract}
Experiment concerning the evaluation of the changes of inorganic phosphorus $(P)$ fractions due to application of cow dung on corn cultivation was conducted in Cibadung village Gunung Sindur, West Java. The rates of cow dung were 0, 10, 20 and 40 tones $\mathrm{ha}^{-1}$. Experiment was designed in completely randomized design with three replications. Soil samples collection were conducted after two weeks incubation and after harvesting. Soil samples were collected in rhizosphere and between rows of corn. The changes of inorganic $P$ fractions were evaluated by the values which were obtained by subtracting the values of one $P$ fraction after two weeks incubation from one $P$ fraction after harvesting. The results showed that the application of cow dung significantly increased the resin- $P_{i}$ fraction, $\mathrm{NaHCO}_{3}-P_{i}$ fraction and $\mathrm{NaOH}-P_{i}$ fraction after two weeks incubation and after harvesting. The values of those $P$ fractions in rhizosphere after harvesting were higher in general than those of between rows of corn. The changes of resin- $P_{i}$ in rhizosphere and in between rows of corn were negatives values indicating that resin$P_{i}$ transformed to other fractions. The changes of $\mathrm{NaHCO}_{3}-P_{i}$ and $\mathrm{NaOH}-P_{i}$ were inconsistently positives values in rhizosphere and in between rows of corn with the increasing rates of cow dung application. They indicated that plant uptake, $P$ desorption and $\mathrm{P}$ transformation to more stable fractions affected the amount of $\mathrm{NaHCO}_{3}-\mathrm{P}_{i}$ and $\mathrm{NaOH}-\mathrm{P}_{i}$ fractions.
\end{abstract}

Keywords: Corn cultivation, cow dung, phosphorus fractions, Ultisol

\begin{abstract}
ABSTRAK
Percobaan mengenai evaluasi perubahan fraksi-fraksi fosfor $(\mathrm{P})$ karena pemberian kotoran sapi pada budidaya jagung dilaksanakan di desa Cibadung Gunung Sindur, Jawa Barat. Dosis kotoran sapi yang digunakan adalah 0, 10, 20, dan 40 ton $\mathrm{ha}^{-1}$. Percobaan dilakukan menggunakan rancangan acak lengkap dengan tiga ulangan. Pengambilan contoh tanah dilakukan setelah dua minggu inkubasi dan setelah panen. Contoh tanah diambil di rhizosfer dan antar baris tanaman. Perubahan fraksifraksi P dievaluasi dari hasil pengurangan nilai suatu fraksi $\mathrm{P}$ pada saat panen dengan nilai suatu fraksi $\mathrm{P}$ setelah dua minggu inkubasi. Hasil menunjukkan bahwa pemberian kotoran sapi nyata meningkatkan fraksi resin- $\mathrm{P}_{\mathrm{i}}$, fraksi NaHCO$-\mathrm{N}_{\mathrm{i}}$ dan NaOH$\mathrm{P}_{\mathrm{i}}$. Nilai fraksi-fraksi $\mathrm{P}$ tersebut pada saat panen lebih tinggi di rhizosfer dibandingkan dengan nilai fraksi-fraksi $\mathrm{P}$ di antar baris tanaman. Perubahan resin- $\mathrm{P}_{\mathrm{i}}$ di rhizosfer dan antar baris tanaman adalah negatif yang menunjukkan bahwa resin- $\mathrm{P}_{\mathrm{i}}$ telah bertransformasi ke fraksi $\mathrm{P}$ yang lain. Perubahan fraksi $\mathrm{NaHCO}_{3}-\mathrm{P}_{\mathrm{i}}$ dan $\mathrm{NaOH}-\mathrm{P}_{\mathrm{i}}$ tidak konsisten positif baik di rhizosfer dan antar baris tanaman dengan meningkatnya dosis kotoran sapi. Hal ini menunjukkan bahwa pengambilan $\mathrm{P}$ oleh tanaman, pelepasan $\mathrm{P}$ dan transformasi $\mathrm{P}$ ke bentuk yang lebih stabil mempengaruhi jumlah peningkatan fraksi $\mathrm{NaHCO}_{3}-\mathrm{P}_{\mathrm{i}}$ dan $\mathrm{NaOH}-$ $\mathrm{P}_{\mathrm{i}}$.
\end{abstract}

Kata kunci: Pertanaman jagung, kotoran sapi, fraksi fosfor, Ultisol

\section{PENDAHULUAN}

Secara kimia faktor pembatas yang ditemui pada lahan kering adalah rendahnya status hara-hara penting bagi tanaman, salah satunya adalah fosfor $(\mathrm{P})$. Menurut Prasetyo dan Suriadikarta (2006) untuk meningkatkan ketersediaan $\mathrm{P}$ di lahan kering dapat dilakukan dengan pengapuran, pemupukan $\mathrm{P}$ dan pemberian bahan organik. Pemberian bahan organik berupa kotoran sapi akan menambah kelarutan $\mathrm{P}$, karena diduga anion dari asam-asam organik dapat melakukan reaksi komplek dengan $\mathrm{Al}$ dan $\mathrm{Fe}$ sehingga $\mathrm{P}$ yang semula terikat oleh $\mathrm{Al}$ dan $\mathrm{Fe}$ dalam bentuk Al-P dan Fe-P menjadi bebas dan tersedia (Iyamuremye et al., 1996a).

Penelitian yang berkaitan dengan pengaruh bahan organik terhadap perubahan fraksi $\mathrm{P}$ telah banyak dilakukan (Iyamuremye et al., 1996b; Hartono et al., 2000), namun penelitian-penelitian tersebut adalah penelitian dengan percobaan inkubasi tanpa melibatkan tanaman. Penelitian pengaruh bahan organik terhadap 
perubahan fraksi $\mathrm{P}$ pada lahan kering dengan melibatkan aktivitas akar tanaman belum banyak dilakukan. Oleh karena itu penelitian ini mengevaluasi bagaimana perubahan fraksi $\mathrm{P}$ pada lahan kering dengan adanya aktivitas tanaman. Adanya aktivitas tanaman diduga akan berpengaruh terhadap dinamika perubahan fraksi $\mathrm{P}$.

Tujuan dari penelitian ini adalah mengevaluasi pengaruh pemberian kotoran sapi terhadap perubahan fraksi-fraksi $\mathrm{P}$ inorganik pada pertanaman jagung di perakaran (rhizosfer) dan antar baris tanaman. Antar baris tanaman ini diasumsikan sebagai daerah yang tidak dipengaruhi oleh akar tanaman.

\section{BAHAN DAN METODE}

Penelitian lapangan dilaksanakan di lahan kering yang terletak di Kecamatan Gunung Sindur, Desa Cibadung, Kabupaten Bogor pada luas lahan total kurang lebih $350 \mathrm{~m}^{2}$. Lahan yang digunakan dalam penelitian mempunyai tanah dengan sub grup Typic Hapludults. Penelitian dilakukan dalam dua tahap pekerjaan. Pekerjaan yang pertama adalah menanam jagung di lapangan. Jagung ditanam pada lahan yang relatif datar di petak-petak percobaan berukuran 10 x $2.55 \mathrm{~m}$. Sebagai perlakuan adalah kotoran sapi. Kotoran sapi yang digunakan mempunyai kadar P total $0.44 \%$ dengan kadar air $26.1 \%$. Sebelum digunakan, kotoran sapi dikeringudarakan kemudian diayak dengan ukuran lubang $2 \mathrm{~mm}$. Perlakuan diberikan dalam empat dosis yaitu $0,10,20$, dan 40 ton ha $^{-1}$ dan masing-masing perlakukan diulang tiga kali. Dengan demikian jumlah petak-petak yang digunakan adalah dua belas petak percobaan. Rancangan percobaan yang diterapkan adalah Rancangan Acak Lengkap. Rancangan acak lengkap digunakan karena petak-petak percobaan terletak di lokasi yang relatif datar.

Sebelum penanaman, kotoran sapi dengan jumlah sesuai dengan dosis perlakuan yang ditetapkan, ditebar secara merata dan diinkorporasi pada kedalaman sekitar 0$20 \mathrm{~cm}$. Kemudian petak-petak tersebut diinkubasi selama dua minggu. Setelah itu penanaman jagung dilakukan dengan jarak tanam 80 × $40 \mathrm{~cm}$. Pengambilan sampel tanah dilakukan pada dua minggu setelah inkubasi (sebelum jagung ditanam) dan setelah panen ketika tanaman berumur sekitar tiga bulan. Pengambilan sampel tanah dilakukan pada kedalaman 0-30 cm. Pengambilan sampel tanah setelah panen dilakukan di antar baris tanaman dan daerah perakaran (rhizosfer) secara komposit.

Pupuk, Urea, SP 18 dan $\mathrm{KCl}$ diberikan sebagai pupuk dasar pada semua petak-petak percobaan. Pupuk Urea, SP 18 dan $\mathrm{KCl}$ yang diberikan tiap petak berturutturut adalah $333 \mathrm{~kg} \mathrm{ha}^{-1}, 280 \mathrm{~kg} \mathrm{ha}^{-1}$, dan $75 \mathrm{~kg} \mathrm{ha}^{-1}$. Pupuk Urea dan $\mathrm{KCl}$ diberikan dalam dua tahap yaitu minggu pertama setelah tanam dan minggu keempat setelah tanam. Sementara pupuk SP 18 diberikan pada saat tanam. Pemeliharaan tanaman dilakukan sampai waktu panen.

Analisis pendahuluan dilakukan untuk mengetahui beberapa sifat kimia dan fisika tanah percobaan. Fraksionasi P inorganik dilakukan dengan menggunakan metode Tiessen dan Moir (1993). Karakterisasi fraksi-fraksi $\mathrm{P}$ inorganik disajikan pada Tabel 1. Evaluasi perubahan fraksi P inorganik dilakukan dengan mengurangi nilai fraksi $\mathrm{P}$ inorganik pada saat panen dengan fraksi $\mathrm{P}$ inorganik setelah 2 minggu inkubasi.

Untuk mengetahui pengaruh perlakuan terhadap parameter-parameter yang ditetapkan dilakukan sidik ragam kemudian diikuti dengan uji Tukey menggunakan Software SPSS V.17.

Tabel 1. Karakterisasi fraksi-fraksi P yang ditetapkan

\begin{tabular}{|c|c|}
\hline Ekstraktan P & $\begin{array}{c}\text { Karakteristik Ekstraktan P } \\
\text { /interpretasi }\end{array}$ \\
\hline \multicolumn{2}{|l|}{ P tersedia secara biologi } \\
\hline \multicolumn{2}{|l|}{ Resin-Pinorganik $\left(\mathrm{P}_{\mathrm{i}}\right)$} \\
\hline dalam $0.5 \mathrm{~mol} \mathrm{~L}^{-1} \mathrm{HCl}$ & P yang tersedia bagi tanaman \\
\hline $0.5 \mathrm{~mol} \mathrm{~L}^{-1} \mathrm{NaHCO}_{3}-\mathrm{P}_{\mathrm{i}}$ & $\begin{array}{l}\text { P yang tersedia bagi tanaman dan terikat } \\
\text { secara lemah pada permukaan mineral }\end{array}$ \\
\hline \multicolumn{2}{|l|}{ Moderately resistant } \\
\hline \multirow[t]{2}{*}{$0.1 \mathrm{~mol} \mathrm{~L}^{-1} \mathrm{NaOH}-\mathrm{P}_{\mathrm{i}}$} & Dierap secara kemisorpsi oleh \\
\hline & hidrusoksida $\mathrm{Al}$ dan $\mathrm{Fe}$ (Al-P dan $\mathrm{Fe}-\mathrm{P})$ \\
\hline
\end{tabular}

HASIL DAN PEMBAHASAN

\section{Sifat Kimia dan Fisika Tanah Percobaan}

Data fisiko kimia tanah percobaan disajikan pada Tabel 2. Status hara tanah dinilai berdasarkan kriteria yang dipublikasikan oleh Soepratohardjo et al.(1983).

Tabel 2. Sifat fisiko kimia tanah percobaan

\begin{tabular}{|c|c|c|}
\hline Sifat & Nilai & Status \\
\hline $\mathrm{pH} \mathrm{H}_{2} \mathrm{O}(1: 1)$ & 5.50 & Masam \\
\hline $\mathrm{P}_{2} \mathrm{O}_{5} \mathrm{HCl} 25 \%\left(\mathrm{mg} 100 \mathrm{~g}^{-1}\right)$ & 44.7 & Tinggi \\
\hline C-organik (\%) & 2.31 & Sedang \\
\hline KTK $\left(\mathrm{cmol} \mathrm{kg}^{-1}\right)$ & 16.8 & Sedang \\
\hline $\mathrm{Al}_{\mathrm{dd}}\left(\mathrm{cmol} \mathrm{kg}^{-1}\right)$ & 0.38 & \\
\hline Kejenuhan $\mathrm{Al}(\%)$ & 10.8 & Rendah \\
\hline $\mathrm{KB}(\%)$ & 20.8 & Rendah \\
\hline Liat $(\%)$ & 41.0 & - \\
\hline Debu $(\%)$ & 53.6 & - \\
\hline Pasir (\%) & 5.38 & - \\
\hline
\end{tabular}

Data $\mathrm{pH}$ tanah percobaan tergolong masam, Corganik masuk dalam kategori sedang, KTK tanah masuk dalam kategori sedang, kejenuhan Al masuk dalam kategori rendah, kejenuhan basa masuk dalam kategori rendah. $\mathrm{P}$ yang diektrak dengan $\mathrm{HCl} 25 \%$ masuk dalam kategori tinggi. Data hasil evaluasi sebagian sifat kimia tanah percobaan relatif baik bila dibandingkan dengan Ultisol pada umumnya. Hal ini mungkin disebabkan karena lokasi percobaan merupakan lahan yang memang diusahakan oleh petani setempat untuk pertanian organik, sehingga beberapa sifat tanah menjadi lebih baik. Kadar liat tanah percobaan adalah $41.0 \%$, debu $53.6 \%$ dan pasir $5.38 \%$. Dengan melihat perbandingan relatif kadar liat, debu dan pasir, tekstur tanah percobaan adalah liat berdebu.

\section{Fraksi Resin-P inorganik (Resin- $\left.\mathbf{P}_{\mathbf{i}}\right)$}

Pengaruh pemberian kotoran sapi terhadap fraksi resin- $\mathrm{P}_{\mathrm{i}}$ disajikan pada Tabel 3 . Tabel 3 menunjukkan bahwa umumnya meningkatnya dosis secara statistik nyata meningkatkan resin- $\mathrm{P}_{\mathrm{i}}$ baik setelah dua minggu inkubasi, saat panen di rhizosfer dan saat panen antar baris tanaman. 
Resin- $\mathrm{P}_{\mathrm{i}}$ adalah fraksi $\mathrm{P}$ yang sangat tersedia (sangat labil) karena berasal dari pertukaran ion bikarbonat dengan ion ortofosfat dalam larutan tanah dan pertukaran ion bikarbonat dengan $\mathrm{P}$ yang diikat sangat lemah oleh komplek erapan. Peningkatan resin- $\mathrm{P}_{\mathrm{i}}$ salah satunya disebabkan oleh mineralisasi kotoran sapi menghasilkan ion ortofosfat yang berada dalam larutan tanah dan proses pemblokan komplek erapan oleh ion-ion asam organik dari kotoran sapi sehingga sebagian $\mathrm{P}$ diikat lemah oleh komplek erapan (Hue, 1991). Untuk daerah rhizosfer, peningkatan resin-Pi juga sebagian disebabkan $\mathrm{P}$ yang berasal dari pupuk selain karena alasan yang sudah disebutkan.

Tabel 3. Pengaruh kotoran sapi terhadap Resin $-\mathrm{P}_{\mathrm{i}}$

\begin{tabular}{|c|c|c|c|c|c|}
\hline \multirow{3}{*}{$\begin{array}{l}\text { Dosis } \\
\text { Kotoran } \\
\text { sapi }\end{array}$} & \multicolumn{5}{|c|}{ Waktu Pengambilan sampel } \\
\hline & $\begin{array}{c}\text { Setelah } 2 \\
\text { minggu } \\
\text { inkubasi }\end{array}$ & $\begin{array}{l}\text { Saat Panen } \\
\text { (rhizosfer) }\end{array}$ & $\begin{array}{c}\Delta \\
\text { Resin- } \\
P_{i}\end{array}$ & $\begin{array}{c}\text { Saat Panen } \\
\text { (antar baris } \\
\text { tanaman) }\end{array}$ & $\begin{array}{c}\Delta \text { Resin- } \\
\mathrm{P}_{\mathrm{i}}\end{array}$ \\
\hline & & & $\mathrm{mg} \mathrm{kg}^{-1}$ & & \\
\hline Kontrol & $123 a$ & $107 \mathrm{a}$ & -16 & $138 \mathrm{a}$ & 15 \\
\hline 10 ton $\mathrm{ha}^{-1}$ & $177 \mathrm{a}$ & $157 b$ & -20 & $150 \mathrm{ab}$ & -27 \\
\hline 20 ton $\mathrm{ha}^{-1}$ & $189 \mathrm{a}$ & $180 \mathrm{c}$ & -9 & $165 b$ & -24 \\
\hline 40 ton $^{-1} \mathrm{p}^{-1}$ & $341 b$ & $227 d$ & -114 & $161 b$ & -180 \\
\hline
\end{tabular}

Keterangan: Angka-angka yang diikutioleh huruf yang sama pada satu kolom, tidak berbeda nyata pada uji Tukey $(\mathrm{P}<0.05)$

Nilai perubahan resin- $\mathrm{P}_{\mathrm{i}}$ (resin- $\mathrm{P}_{\mathrm{i}}$ saat panen resin- $\mathrm{P}_{\mathrm{i}}$ setelah dua minggu inkubasi) umumnya bernilai negatif baik di rhizosfer dan di antar baris yang kurang dipengaruhi oleh aktifitas akar tanaman jagung (Tabel 3). Hal ini mengkonfirmasi hasil penelitian Hartono et al. (2006) bahwa resin- $\mathrm{P}_{\mathrm{i}}$ bertransformasi menjadi bentuk fraksi-fraksi yang lain dengan waktu pada percobaan inkubasi. Disamping itu resin- $\mathrm{P}_{\mathrm{i}}$ diambil oleh tanaman terutama yang berada di daerah rhizosfer.

Perbedaan resin- $\mathrm{P}_{\mathrm{i}}$ di rhizosfer saat panen dan resin- $P_{i}$ di antar baris tanaman saat panen disebabkan oleh pelepasan eksudat akar oleh tanaman di rhizosfer dan pupuk P. Eksudat akar dan pupuk $\mathrm{P}$ yang diberikan di sekitar tanaman meningkatkan konsentrasi resin- $\mathrm{P}_{\mathrm{i}}$ di daerah rhizosfer.

\section{Fraksi $\mathrm{NaHCO}_{3}-\mathrm{P}_{\mathrm{i}}$}

Pengaruh kotoran sapi terhadap fraksi $\mathrm{NaHCO}_{3}-\mathrm{P}_{\mathrm{i}}$ disajikan pada Tabel 4. Fraksi $\mathrm{NaHCO}_{3}-\mathrm{P}_{\mathrm{i}}$ juga merupakan fraksi yang relatif tersedia (labil). Fraksi ini diikat lebih kuat daripada fraksi resin- $\mathrm{P}_{\mathrm{i}}$ oleh komplek erapan. Dosis 40 ton ha ${ }^{-1}$ secara statistik nyata meningkatkan $\mathrm{NaHCO}_{3}-\mathrm{P}_{\mathrm{i}}$ baik setelah 2 minggu inkubasi, saat panen di rhizosfer dan saat panen antar baris tanaman. Alasan yang sama dengan pembahasan mengenai fraksi resin- $\mathrm{P}_{\mathrm{i}}$ dapat dikaitkan dengan peningkatan ini.

Nilai perubahan $\mathrm{NaHCO}_{3}-\mathrm{P}_{\mathrm{i}}\left(\mathrm{NaHCO}_{3}-\mathrm{P}_{\mathrm{i}}\right.$ saat panen - $\mathrm{NaHCO}_{3}-\mathrm{P}_{\mathrm{i}}$ setelah dua minggu inkubasi) di rhizosfer dan antar baris tanaman bernilai positif untuk perlakuan kontrol dan 10 ton $\mathrm{ha}^{-1}$. Hal ini menunjukkan bahwa ada resin- $\mathrm{P}_{\mathrm{i}}$ bertransformasi ke fraksi ini. Resin- $\mathrm{P}_{\mathrm{i}}$ yang merupakan $\mathrm{P}$ dalam larutan tanah dan $\mathrm{P}$ yang diikat sangat lemah oleh komplek erapan dengan waktu akan dierap lebih kuat oleh komplek erapan sehingga salah satunya menjadi bentuk $\mathrm{NaHCO}_{3}-\mathrm{P}_{\mathrm{i}}$. Akan tetapi angka yang berasal dari resin- $\mathrm{P}_{\mathrm{i}}$ terlalu kecil untuk angka peningkatan $\mathrm{NaHCO}_{3}-\mathrm{P}_{\mathrm{i}}$ yang terjadi, sehingga peningkatan juga mungkin berasal dari pupuk $\mathrm{P}$ yang diberikan terutama untuk daerah rhizosfer. Selain itu, penambahan $\mathrm{P}$ dari eksudat akar juga dapat dikaitkan dengan lebih tingginya fraksi ini di daerah rhizosfer. Walaupun demikian hal ini tidak berlaku untuk yang dosis 40 ton $\mathrm{ha}^{-1}$. Perbedaan ini menunjukkan bahwa aktivitas tanaman mengambil hara, pelepasan $\mathrm{P}$ (P desorption) dan perubahan ke fraksi yang lebih stabil memberikan dinamika terhadap proses transformasi $\mathrm{P}$.

Tabel 4. Pengaruh kotoran sapi terhadap $\mathrm{NaHCO}_{3}-\mathrm{P}_{\mathrm{i}}$

\begin{tabular}{|c|c|c|c|c|c|}
\hline \multirow[b]{2}{*}{$\begin{array}{l}\text { Dosis } \\
\text { kotoran } \\
\text { sapi }\end{array}$} & \multicolumn{5}{|c|}{ Waktu Pengambilan sampel } \\
\hline & $\begin{array}{c}\text { Setelah } 2 \\
\text { minggu } \\
\text { inkubasi }\end{array}$ & $\begin{array}{c}\text { Saat } \\
\text { panen } \\
\text { (rhizosfer) }\end{array}$ & $\begin{array}{c}\Delta \\
\mathrm{NaHCO}_{3}- \\
\mathrm{P}_{\mathrm{i}}\end{array}$ & $\begin{array}{c}\text { Saat Panen } \\
\text { (antar baris } \\
\text { tanaman) }\end{array}$ & $\begin{array}{c}\Delta \\
\mathrm{NaHCO}_{3}- \\
\mathrm{P}_{\mathrm{i}}\end{array}$ \\
\hline & & & $\mathrm{mg} \mathrm{kg}^{-1}$ & & \\
\hline Kontrol & $131 \mathrm{a}$ & $206 \mathrm{a}$ & 75 & $172 \mathrm{a}$ & 40 \\
\hline 10 ton $\mathrm{ha}^{-1}$ & $195 \mathrm{ab}$ & $241 b$ & 46 & $221 \mathrm{ab}$ & 26 \\
\hline 20 ton $\mathrm{ha}^{-1}$ & $256 a b$ & $259 b$ & 3 & $252 b$ & -4 \\
\hline 40 ton $\mathrm{ha}^{-1}$ & $350 \mathrm{~b}$ & $336 \mathrm{c}$ & -14 & $241 b$ & -109 \\
\hline
\end{tabular}

Keterangan: Angka-angka yang diikuti oleh huruf yang sama pada satu kolom, tidak berbeda nyata pada uji Tukey $(\mathrm{P}<0.05)$

\section{Fraksi NaOH-P}

Pengaruh kotoran sapi terhadap fraksi $\mathrm{NaOH}-\mathrm{P}_{\mathrm{i}}$ disajikan pada Tabel 5. Angka-angka $\mathrm{NaOH}-\mathrm{P}_{\mathrm{i}}$ jauh lebih besar dibandingkan dengan resin- $\mathrm{P}_{\mathrm{i}}$ dan $\mathrm{NaHCO}_{3}-\mathrm{P}_{\mathrm{i}}$. Fraksi ini adalah $\mathrm{P}$ yang dierap oleh hidrusoksida $\mathrm{Fe}$ dan Al menjadi senyawa Fe-P dan Al-P. Besarnya nilai $\mathrm{NaOH}-$ $\mathrm{P}_{\mathrm{i}}$ dibandingan dengan resin- $\mathrm{P}_{\mathrm{i}}$ dan $\mathrm{NaHCO}_{3}-\mathrm{P}_{\mathrm{i}}$ karena $\mathrm{P}$ dalam larutan tanah dengan sangat cepat dierap oleh hidrusoksida $\mathrm{Fe}$ dan $\mathrm{Al}$ dalam jumlah besar menjadi bentuk Fe-P dan Al-P yang relatif resisten (Hartono et al., 2006). Dari dosis kotoran sapi yang diaplikasikan dosis 20 dan 40 ton ha $^{-1}$ secara statistik nyata meningkatkan $\mathrm{NaOH}$ $\mathrm{P}_{\mathrm{i}}$ setelah 2 minggu inkubasi.

Pengaruh kotoran sapi tidak nyata meningkatkan $\mathrm{NaOH}-\mathrm{P}_{\mathrm{i}}$ pada saat panen baik di rhizosfer dan antar baris tanaman. Walaupun demikian kecuali perlakuan 40 ton ha $^{-1}$, angka NaOH- $\mathrm{P}_{\mathrm{i}}$ di daerah rhizosfer relatif lebih tinggi dibandingkan dengan angka $\mathrm{NaOH}-\mathrm{P}_{\mathrm{i}}$ di antar baris tanaman.

Tabel 5. Pengaruh kotoran sapi terhadap $\mathrm{NaOH}-\mathrm{P}_{\mathrm{i}}$

\begin{tabular}{|c|c|c|c|c|c|}
\hline \multirow{3}{*}{$\begin{array}{l}\text { Dosis } \\
\text { kotoran } \\
\text { sapi }\end{array}$} & \multicolumn{5}{|c|}{ Waktu Pengambilan sampel } \\
\hline & $\begin{array}{c}\text { Setelah } 2 \\
\text { minggu } \\
\text { inkubasi }\end{array}$ & $\begin{array}{l}\text { Saat Panen } \\
\text { (rhizosfer) }\end{array}$ & $\begin{array}{c}\Delta \\
\mathrm{NaOH}- \\
\mathrm{P}_{\mathrm{i}} \\
\end{array}$ & $\begin{array}{c}\text { Saat Panen } \\
\text { (antar baris } \\
\text { tanaman) }\end{array}$ & $\begin{array}{c}\Delta \\
\mathrm{NaOH}- \\
\mathrm{P}_{\mathrm{i}}\end{array}$ \\
\hline & & & $\mathrm{mg} \mathrm{kg}^{-1}$ & & \\
\hline Kontrol & $404 \mathrm{a}$ & $523 a$ & 119 & $517 \mathrm{a}$ & 113 \\
\hline 10 ton $\mathrm{ha}^{-1}$ & $451 \mathrm{a}$ & $555 \mathrm{a}$ & 54 & $547 \mathrm{a}$ & 96 \\
\hline 20 ton $\mathrm{ha}^{-1}$ & $651 b$ & $601 \mathrm{a}$ & -50 & $596 a$ & -55 \\
\hline 40 ton ha $^{-1}$ & $764 \mathrm{c}$ & $626 a$ & -138 & $634 a$ & -130 \\
\hline
\end{tabular}

Nilai perubahan $\mathrm{NaOH}-\mathrm{P}_{\mathrm{i}}\left(\mathrm{NaOH}-\mathrm{P}_{\mathrm{i}}\right.$ saat panen $\mathrm{NaOH}-\mathrm{P}_{\mathrm{i}}$ setelah dua minggu inkubasi) bernilai positif untuk kontrol dan dosis 10 ton ha ${ }^{-1}$ baik di daerah rhizosfer dan antar baris tanaman. Akan tetapi bernilai negatif untuk dosis 20 dan 40 ton ha $^{-1}$. Hal ini menunjukkan bahwa ada bentuk $\mathrm{P}$ yang bertransformasi ke fraksi ini. Nilai perubahan fraksi ini yang bernilai negatif pada dosis 20 
dan 40 ton ha $^{-1}$ menunjukkan bahwa fraksi ini bukan fraksi yang stabil pada tanah percobaan ini. Akan tetapi fraksi ini bisa memberikan $\mathrm{P}$ jika terjadi pengurangan dengan fraksi yang tersedia atau labil karena pengambilan oleh tanaman (Hartono, 2008) atau terjadi transformasi menjadi bentuk yang lebih stabil.

\section{SIMPULAN}

Semakin tinggi dosis kotoran sapi yang diberikan sebagai bahan amelioran secara umum meningkatkan nilai-nilai fraksi resin- $\mathrm{P}_{\mathrm{i}}, \mathrm{NaHCO}_{3}-\mathrm{P}_{\mathrm{i}}$, dan $\mathrm{NaOH}-\mathrm{P}_{\mathrm{i}}$ setelah dua minggu masa inkubasi dan setelah panen pada tanah di bawah pertanaman jagung. Secara umum nilainilai fraksi resin- $\mathrm{P}_{\mathrm{i}}, \mathrm{NaHCO}_{3}-\mathrm{P}_{\mathrm{i}}$ dan $\mathrm{NaOH}-\mathrm{P}_{\mathrm{i}}$ saat panen di daerah rhizosfer lebih tinggi dibandingkan dengan antar baris tanaman.

Nilai fraksi resin- $\mathrm{P}_{\mathrm{i}}$ secara umum menurun setelah panen yang mengindikasikan bahwa resin- $\mathrm{P}_{\mathrm{i}}$ telah bertransformasi menjadi bentuk-bentuk fraksi $\mathrm{P}$ yang lain dan diambil oleh tanaman. Nilai fraksi $\mathrm{NaHCO}_{3}-\mathrm{P}_{\mathrm{i}}$ setelah panen relatif tidak konsisten meningkat yang menunjukkan bahwa fraksi ini bisa meningkat karena hasil dari transformasi resin- $\mathrm{P}_{\mathrm{i}}$ atau menurun karena diambil oleh tanaman, pelepasan $\mathrm{P}$ ( $\mathrm{P}$ desorption) dan bertransformasi menjadi bentuk yang lebih resisten.

Fraksi $\mathrm{NaOH}-\mathrm{P}_{\mathrm{i}}$ yang didefinisikan sebagai fraksi yang moderately resistant juga tidak konsisten meningkat yang menunjukkan bahwa fraksi $\mathrm{NaOH}-\mathrm{P}_{\mathrm{i}}$ bukan fraksi yang stabil. Fraksi $\mathrm{NaOH}-\mathrm{P}_{\mathrm{i}}$ diduga meningkat karena terjadi transformasi dari bentuk fraksi $\mathrm{P}$ yang labil menjadi fraksi $\mathrm{NaOH}-\mathrm{P}_{\mathrm{i}}$ atau menurun karena fraksi $\mathrm{NaOH}-\mathrm{P}_{\mathrm{i}}$ memberikan $\mathrm{P}$ (P desorption) ke fraksi yang labil jika terjadi pengurangan konsentrasi fraksi $\mathrm{P}$ yang labil karena diambil oleh tanaman.

\section{UCAPAN TERIMA KASIH}

Penulis mengucapkan terima kasih kepada Dr. Tetsuhiro Watanabe, staf Laboratory of Soil Science, Kyoto University yang telah mendanai penelitian ini.

\section{DAFTAR PUSTAKA}

Hartono, A. 2008. Releasing pattern of applied phosphorus and distribution change of phosphorus fractions in the acid upland soils with successive resin extraction. J. Tanah Trop., 13:87-94.

Hartono, A., P.L.G. Vlek, A. Moawad, and A. Rachim. 2000. Changes in phosphorus fractions on acidic soil induced by phosphorus fertilizer, organic matter and lime. J. Ilmu Tanah dan Lingk., 3:1-7.

Hartono, A., S. Funakawa, and T. Kosaki. 2006. Tranformation of added phosporus to different acid soil properties in Indonesia. Soil Sci. and Plant Nutr., 52:734-744.

Hue, N.V. 1991. Effect of organik acids/anions on $\mathrm{P}$ sorption and phytoavailability in Soil with different mineralogies. Soil Sci., 152:462-471.

Iyamuremye, F., R.P. Dick, and J. Baham. 1996a. Organic amandement and phosphorus dynamics: I. Phosphorus chemistry and sorption. Soil Sci., 161:426-435.

Iyamuremye, F., R.P. Dick, and J. Baham. 1996b. Organic amendments and phosphorus dynamics: II. Distribution of soil phosphorus fractions. Soil Sci., 161:436-443.

Prasetyo, B.H. dan D.A. Suriadikarta. 2006. Karakteristik, potensi, dan teknologi pengelolaan tanah Ultisol untuk pengembangan pertanian lahan kering di Indonesia. Jurnal Litbang Pertanian, 25:39-47.

Soepratohardjo, M., Subagjo, H. Suhardjo, Ismangun, D.S. Marsoedi, A. Hidayat, Y. Dai, A. Adi, M. Supartini, Mursidi, dan J. Sri Adiningsih S. 1983. Terms of Reference Survai Kapabilitas Tanah. Pusat Penelitian Tanah. Bogor.

Tiessen, H. and J.O. Moir. 1993. Characterization of Available $P$ by Sequential Extraction. dalam Carter MR (Ed.). Soil Sampling and Methods of Analysis. Lewis Publishers. Canadian Society of Soil Science. pp.75-86 
